\title{
Effect of an Educational Program on Nurses' Performance Regarding Nursing Intervention for Infants Undergoing Inguinal Hernia Repair
}

\section{Fatma Abdel-Satar Dosokey Ali ${ }^{1}$, Rahma Soliman Bahgat ${ }^{2}$, Basma Rabie Abdel-Sadik ${ }^{3}$ and Khadiga Mohammed Said ${ }^{4}$}

(1) Pediatric Nursing, Faculty of nursing, Benha University (2) Prof. Dr., pediatric Nursing, Faculty

of nursing, Tanta University (3) Assist. Prof. Dr., pediatric Nursing, Faculty of nursing, Benha

University (4) Assist. Prof. Dr., pediatric Nursing, Faculty of nursing, Benha Nniversity.

\begin{abstract}
Background Inguinal Hernia $(\mathrm{IH})$ occurs when the contents of the abdomen usually fat or part of the small intestine bulge through a weak area in the groin region. Inguinal hernia is the most common surgical problem in infancy period. Nursing care is an integral part of managing infants undergoing IH repair. The study aimed to evaluate the effect of an educational program on nurses' performance regarding nursing intervention for infants undergoing inguinal hernia repair. Design: A quasiexperimental design was used to conduct this study. Setting: The study was conducted at pediatric surgery units of Benha Specialized Pediatric Hospital. Sampling: A Convenient purposive sample was comprised of 30 nurses and a convenient sample of 283 infants who were undergoing inguinal hernia repair at the previously mentioned study setting. Tools of Data Collection: Two tools were used: tool (I): a structured interviewing questionnaire sheet included three parts, tool (II): nurses' observational checklists included pre and postoperative nursing intervention. The results of this study revealed that, the majority of the studied nurses had good level of knowledge, and competent level of practice post program intervention with highly statistical significant improvement as compared to preprogram intervention. Moreover, there were positive correlation between the studied nurses' total knowledge and practice scores regarding pre and postoperative nursing care for infants undergoing inguinal hernia repair pre and immediately post program intervention and follow up intervention. The study concluded that, educational program was effective in improving nurses' performance regarding nursing intervention for infants undergoing inguinal hernia repair. The study recommended: Inservice training programs should be conducted periodically for teaching the nurses the basic knowledge and clinical skills for infants undergoing IH and other surgeries.
\end{abstract}

Key words: Inguinal hernia, Infants, Educational program, Nurses’ performance.

\section{Introduction}

The first year of life is one of the most critical stages in childhood development. Infancy period begins from one month to 12 month in which there is rapid growth and development. During the first 12 months, infants should be examined regularly to determine proper development and identify any health problems. Early detection and treatment of potential problems are vital to an infant's development. Inguinal hernia (IH) can occur at any age, but the peak incidence is during infancy period and early childhood with 80$90 \%$ occurring in males. One third of infancy and childhood hernias appear in the first 6 months of life (Ashcraft et al., 2016). 
Inguinal hernia develops when a sac containing a piece of the bowel, or one of the layers of tissue that coat the organs inside the abdomen, bulges out through the muscles of the abdominal wall to create a lump in the groin or scrotum. As a male infant grows during pregnancy; the testicles develop in the abdomen. Then they move down into the scrotum through the inguinal canal. Shortly after the infant is born, the inguinal canal closes. This stops the testicles from moving back into the abdomen. If this area does not fully close, a part of the intestine can move into the canal through the weakened area of the lower abdominal wall, and cause hernia. Although girls don't have testicles, they do have an inguinal canal. So they can also have hernias in the groin (Abdelghaffar, 2017) \& (Daral, 2019).

Inguinal hernia firstly appears as a bulge in the groin, and may appear and disappear, or may be present all the time. Sometimes the hernia will be visible only when an infant is crying, coughing or straining during a bowel movement. The infant might be irritable and have less appetite than usual.

Symptoms of an incarcerated or a strangulated hernia include extreme tenderness or painful redness in the area of the bulge in the groin, sudden pain that worsens quickly and does not go away, the inability to have a bowel movement and pass gas, fever, nausea and vomiting (Puri, 2018).

Nursing interventions for infants undergoing inguinal hernia repair include pre and post-operative care, the nurse provides preoperative instructions related feeding as infant should fast 4 hour from formula, inserts peripheral intravenous line, monitors vital signs, prepares infants physical and psychological for surgery.in addition the nurse is responsible for routine post-operative observations as full cardiac and oxygen saturation monitoring for 24 hours, hourly temperature and blood pressure for 4 hours or until stable, then 4 hourly. The nurse should observer wound site for bleeding, swelling and redness, monitor pain scores, administer pain relief if indicated consider feeding and maintain an accurate record of input and output (Tkaz \& Carmel, 2016).

\section{Significance of the study:-}

Repair of inguinal hernia is considered the most frequently procedure among surgical procedures performed in infancy. Most pediatric ventral and inguinal hernias are detected in the first year of life. Inguinal hernias in both term and preterm infants are commonly repaired shortly after diagnosis to avoid incarceration of the hernia. In infants and young children, the risk of incarceration of the unrepaired inguinal hernia is as high as $31 \%$ (Abdelmohsen et al., 2017). Therefore, the present study was conducted to determine the effect of an educational program on nurses' performance regarding nursing intervention for infants undergoing inguinal hernia repair.

\section{Aim of the study}

This study aims to evaluate the effect of an educational program on nurses' performance regarding nursing intervention for infants undergoing inguinal hernia repair through:-

1-Assessing nurses' knowledge and practice regarding nursing intervention for infants undergoing inguinal hernia repair.

2-Designing and implementing an educational program for nurses regarding nursing intervention for infants undergoing inguinal 
hernia repair based on actual nurses' needs assessment.

3-Evaluating the effect of an educational program on nurses' knowledge and practice regarding nursing intervention for infants undergoing inguinal hernia repair.

\section{Research hypothesis}

Nurses' knowledge and practice was improved after implementation of an educational program regarding nursing intervention for infants undergoing inguinal hernia repair.

\section{Subjects and method}

\section{Research design:-}

A quasi-experimental research design was utilized to conduct this study (one group for pre, post and follow up test).

\section{Research setting:}

This study was carried out at Pediatric Surgery Units of Benha Specialized Pediatric Hospital, affiliated to The Egyptian Ministry of Health and Population. This unit comprised two rooms for stable cases and one Intermediate Intensive Care Unit. Each of the 2 rooms are equipped and consisted of 8 beds .The intermediate ICU unit includes 6 beds, mechanical ventilator and an incubator. Research subjects:-

(I) A Convenient sample of all available nurses $(n=30)$ working at the previously mentioned study setting regardless of their personal characteristics.

(II) A Convenient sample of all available infants who were undergoing inguinal hernia repair $(n=283)$ throughout pre, post and follow up assessment at the previously mentioned study setting.

\section{Tools of Data Collection:-}

Data collected through using the following two tools:-

\section{Tool I: A structured Interviewing Questionnaire Sheet:}

This tool developed by the researcher under thesis supervisors after reviewing related literature (Matti, 2017). It was written in simple Arabic language to suit the nurses' level of understanding. It composed of three parts as following:

Part 1: -Characteristics of studied nurses such as; age, qualification, years of experience, attendance of training programs regarding inguinal hernia and nursing intervention for infants undergoing inguinal hernia repair.

Part 2: - Characteristics of studied infants such as; gender, age, medical diagnosis, birth order and postoperative complications.

Part 3: a- Nurses' knowledge regarding inguinal hernia as: Definition, types, signs and symptoms, risk factors, complications, diagnosis of inguinal hernia, affected age, indications for inguinal hernia repair and dangerous sigs of inguinal hernia.

b- Nurses' knowledge regarding nursing intervention for infants undergoing inguinal hernia repair as:

Pre and post-operative nursing care, fever management, wound infection management and heath teaching for infants' caregiver.

\section{The total scoring system of nurses ' knowledge:}

Nurses ' knowledge were evaluated upon completion of the interviewing questionnaire sheet as the studied nurses' knowledge was checked with a model key answer and accordingly the correct and complete answer was given score (2), correct and incomplete answer was given score (1) and wrong answer or don't know was given score (0). The total score for all 19 questions was 38 degree which represents $100 \%$. 
The total scoring system of nurses' knowledge was classified into three levels as the following:

$75-\leq 100 \%$ was considered good knowledge.

$60-<75 \%$ was considered fair knowledge.

$<60 \%$ was considered poor knowledge.

\section{Tool II: Nurses Observational Checklists:}

This tool was adopted from Hockenberry \& Wilson, (2015) and Doughetry \& Lister, (2015). It was used to assess the actual nurses' practice regarding nursing intervention for infants undergoing inguinal hernia repair pre and post operatively, before, immediately after and after 12 weeks. It was included the following:-

- Preoperative nursing intervention such as: preoperative care, physical assessment, length, weight.

- Post-operative nursing interventions such as: Immediate postoperative care , hand washing, vital signs, feeding, Wound care, medication administration, measures to reduce fever, recording and reporting

Scoring system for nurses' practice was as the following:

The score of each item in the observational checklists was ranged as the following: correctly done and complete was scored (1) and incorrectly done or not done was scored (0). The total number of checklists was 13 checklists with total number of the items168; so the total scores of the items were (168) degree.

Scoring system for nurses' practice was calculated as the following:

$75-\leq 100 \%$ was considered satisfactory. $<75 \%$ was considered unsatisfactory.

\section{II- Operational Design:}

The operational design included preparatory phase, validity and reliability, ethical considerations, pilot study and field work.

\section{Preparatory Phase:}

The current, past, local and international available related literatures concerning the research problem, was reviewed by the researcher under thesis supervisors using articles, magazines, books and internet search to be acquainted with research problem as well as developed the study tools.

\section{Validity and reliability of study tool:}

The developed tools were validated by a jury consisted of three experts in the field of pediatric nursing in pediatric nursing department at Benha University to determine the extent to which the items in the study tools were related to each other, tested clarity, relevance, comprehensiveness, simplicity and applicability. The jury group members' response to the standards statement and its criteria with either agree or disagree and comments, accordingly minor modifications were done. Reliability of the tools was applied by the researcher for testing the internal consistency of the tool by administration of the same tool to the same subjects under similar condition; it was done by using cronbach's coefficiency alpha test. Reliability of knowledge equal 0.81 , reliability of practice equal 0.76 .

\section{Ethical considerations:}

The researcher explained the aim of the study to the director of the hospital for taking permission for conducting the study and ensured that each participant approved to be involved in the study. A brief explanation of study was given to assure nurses that information obtained are confidential and used only for the purpose of the study and maintained privacy and took oral consent for 
participation and all nurses were given the right to withdraw from the study at any time without any explanation of any rationale. Also, an oral consent was taken from the studied infants' mothers.

\section{Pilot study:}

A pilot study was carried out during February 2019 for one month involved 10\% of studied subjects ( 3 nurses and 28 infant). It was done to evaluate the reliability and validity of the study tools, and estimate proper time required for answering the questionnaire, where no radical modifications were carried out in the study tools as revealed from pilot study. The pilot was included in the study

\section{Field work:}

The actual data collection was started from the beginning of April 2019 to the end of December 2019. The researcher was available in the study setting two days per week (Monday and Tuesday) during (morning and afternoon shifts) to collect data by using previous tools. The current study was carried out through the following phases:-

\section{a- Assessment phase:}

The researcher interviewed each nurse individually; first, the researcher introduced herself to nurses, explained the aim of the study and oral consent was obtained to participate in the study prior to data collection. The researcher administer the questionnaire sheet to nurses individually to assess their personal characteristics, knowledge about inguinal hernia and nursing intervention for infants undergoing inguinal hernia repair and explanation of the questionnaire sheet was done by the researcher. The average time needed for completion of questionnaire was between 20-25 minutes. Nurses' practice was observed by using observational checklists during their actual practice. Each infant with inguinal hernia was assessed by the researcher and data was collected from the medical record.

\section{b- Planning phase:}

After assessing nurses' knowledge and practice, the researcher designed an educational program about nursing intervention for infants undergoing inguinal hernia repair.

\section{c- Implementation phase:}

Implementation phase was achieved through 10 sessions at a period of 10 weeks. The total number of studied nurses was 30 who divided into 6 equal groups; each group consisted of 5 nurses to collect the related information. The total number of sessions was 10 which were divided as follows: four sessions for knowledge and six sessions for practice. The time of knowledge session was 30 minutes and the duration of practice session ranged between 45 to 60 minutes. The researcher was available in the study setting two days per week (Monday and Tuesday) during (morning and afternoon shifts) and the educational program was implemented according to nurses' readiness.

These sessions were repeated to each subgroup of nurses. Also, sessions of practice were implemented in the form of demonstration and re-demonstration for each group. Each session started with a summary of the previous session and objectives of the new one. Taking into consideration the use of Arabic language that suits the nurses' educational level. Motivation and reinforcement during session were used in order to enhance motivation for participation in the study. The researcher continued to reinforce the gained information, answered any 
raised questions and gave feedback. Each nurse was supplemented with the printed booklet.

Teaching methods were different as group discussion, lecture, demonstration and redemonstration. The researcher used various teaching media in the form of colored pictures, booklet, as well as video and power point.

\section{d- Evaluation phase:}

Nurses' knowledge and practice were evaluated immediately and 12 weeks after implementation of educational program intervention (posttest) and after 12 weeks as follow up test.

\section{III- Administrative design:}

An official permission for data collection was taken from the Dean of Faculty of Nursing, Benha University, Hospital director and Chairman of pediatric surgery department at Benha Specialized Pediatric Hospital to carry out the study. The objectives \& expected outcomes and the nature of the study were explained.

\section{IV-Statistical design:}

The collected data was organized, coded, computerized, tabulated and analyzed by using the Statistical Package for Social Science (SPSS), version (20). Data analysis was accomplished by the use of frequencies, percentages for qualitative descriptive data, and chi-square $\left(\mathrm{X}^{2}\right)$ was used for relation tests, mean and standard deviation was used foe quantitative data, person correlation coefficient (r) was used for correlation analysis and degree of significance was identified.

\section{Results}

Table (1) shows characteristics of studied nurses. It revealed that two thirds $66.6 \%$ of the studied nurses' age was 30 years and more with a mean age $\mathbf{3 1 . 2 0 \pm 5 . 2 5}$ years. In relation to regarding nursing intervention for infants undergoing IH repair using tool (1) and (2). Immediate posttests were carried out to evaluate nurses' knowledge and practice using the same forms of pretest, this helped to evaluate the effect of educational program on nurses' performance regarding nursing intervention for infants undergoing inguinal hernia repair. The posttests were done immediately after the implementation of

nurses' qualification, more than half of the studied nurses $53.3 \%$ had secondary nursing school, $30 \%$ of them had technical institute of nursing. Regarding years of experience, $63.3 \%$ of them had 10 years and more with a mean years of experience $11.60 \pm 6.33$ years.

Table (2) shows characteristics of the studied infants. It was found that the majority $82 \%$ of the studied infants' age was less than 6 months with a mean age $\mathbf{3 . 7 3} \pm \mathbf{3 . 1 4}$ month. Regarding to birth order, this table clarifies that $40.3 \%$ of the studied infants' were the first infant, while more than one third $38.5 \%$ of them were the second infant in the family. Regarding gender, it illustrated that more than three quarters $78.1 \%$ of studied infants undergoing inguinal hernia repair were males.

Figure (1) shows inguinal hernia type, it clarified that more than one third $36 \%$ of studied infants were diagnosed with right inguinal hernia

Figure (2) shows that the majority $82.3 \%$ of studied infants had not family history of inguinal hernia. In addition the minority $17.7 \%$ of them had family history of inguinal hernia.

Figure (3) shows nurses' total knowledge score through the program phases, it revealed that, 
less than quarter $23.3 \%$ of studied nurses had good knowledge regarding total knowledge score about $\mathrm{IH}$ and nursing care of infant undergoing inguinal hernia repair in preprogram intervention. While the majority $80 \%$ of studied nurses had good knowledge regarding total knowledge score about inguinal hernia (IH) and nursing care of infant undergoing inguinal hernia repair in post program intervention. Moreover more than half of them 56.7\% scored good in follow up program intervention.

Figure (4) shows nurses' total practice regarding nursing care of inguinal hernia repair through the program phases, it revealed that, less than half $(46.7 \%)$ were scored satisfactory in their practice preprogram intervention, while the majority $(80 \%)$ of studied nurses were scored satisfactory in their practice post program intervention and less than three quarters $(73.3 \%)$ of them were scored satisfactory in their practice follow up program intervention.

Table (3) Shows correlation between total knowledge and total practices among studied nurses through the program phases. It revealed that there is a positive relation between total knowledge scores of studied nurses and their total practice scores at pre and immediately post intervention and follow up intervention ( $\mathbf{P}$ $<0.001$ )

Table (1): Percentage distribution of studied nurses regarding their characteristics

\begin{tabular}{|l|c|c|}
\hline \multirow{2}{*}{ Nurses' characteristics } & \multicolumn{2}{c|}{ Total No. =30 } \\
\cline { 2 - 3 } & No. & \% \\
\hline \hline Age in years: & 5 & \\
\hline $20-<25$ & 5 & 16.7 \\
$25-<30$ & 20 & 66.7 \\
30 and more Mean \pm SD & & \\
\hline \multicolumn{2}{|c|}{$\mathbf{3 1 . 2 0} \pm \mathbf{5 . 2 5}$} \\
\hline Qualification: & 16 & 53.3 \\
\hline - Secondary nursing school. & 9 & 30.0 \\
- Technical institute of nursing. & 5 & 16.7 \\
- Bachelor of nursing science & 6 & \\
\hline Years of experience: & 5 & 20.0 \\
\hline $0-<5$ & 19 & 63.3 \\
$5-<10$ & & \\
10 and more & \\
\hline \multicolumn{2}{|c|}{ Mean \pm SD } \\
\hline
\end{tabular}


Table (2): Percentage distribution of studied infants regarding their characteristics

\begin{tabular}{|c|c|c|}
\hline Infant characteristics & $\mathrm{n}=283$ & $\%$ \\
\hline \multicolumn{2}{|c|}{ Age in months } \\
\hline$<$ 6 months & 232 & $\mathbf{8 2 . 0}$ \\
\hline 6- $\leq$ 12 months & 51 & 18.0 \\
\hline Mean \pm SD & $3.73 \pm 3.14$ month \\
\hline \multicolumn{3}{|c|}{ Birth order } \\
\hline First & 114 & 40.3 \\
\hline Second & 109 & 38.5 \\
\hline Third & 60 & 21.2 \\
\hline Male & 221 & 78.1 \\
\hline Female & 62 & 21.9 \\
\hline
\end{tabular}

\section{Type of hernia}

$\begin{array}{ll}\text { Right inguinal hernia } & \text { Left inguinal hernia } \\ \text { Bilateral inguinal hernia } & \text { Irreducible inguinal hernia } \\ \text { Strangulated inguinal hernia } & \text { Recurrent inguinal hernia }\end{array}$

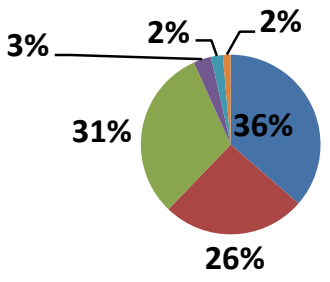

Figure (1): Distribution of studied infants regarding type of inguinal hernia.

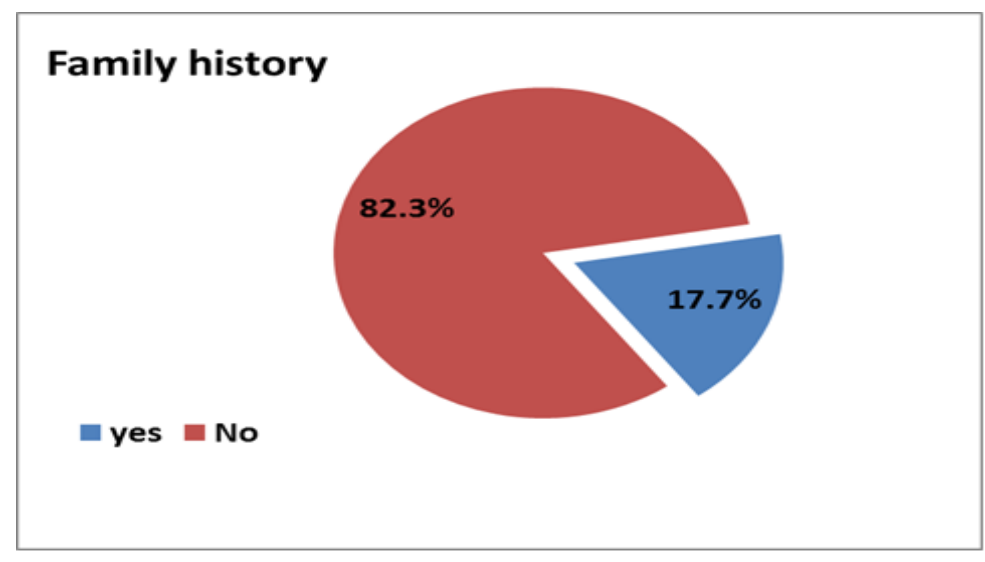

Figure (2): Distribution of studied infants regarding family history of inguinal hernia 


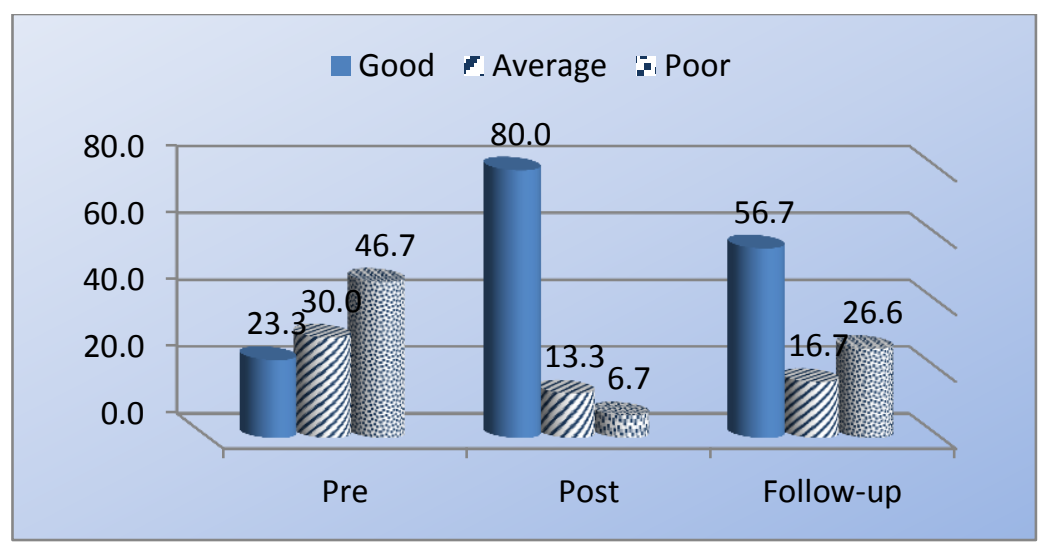

Figure (3): Distribution of studied nurses regarding total score of knowledge through the program phases

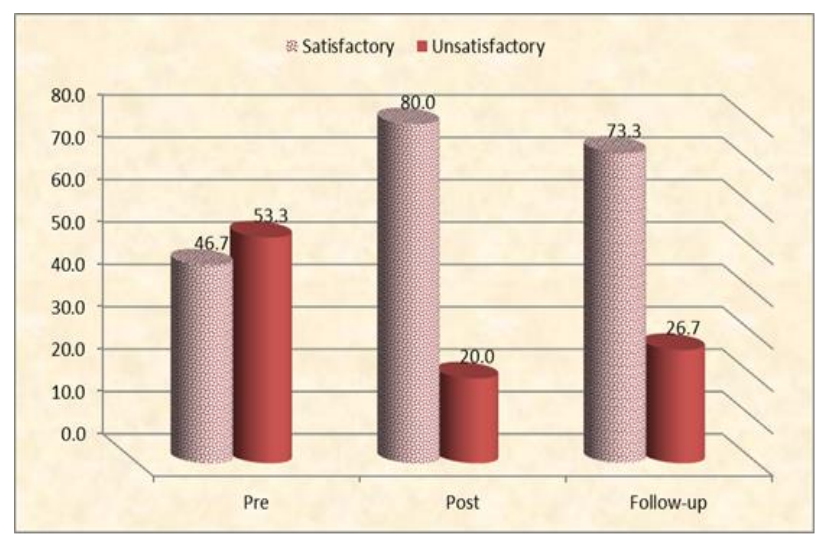

Figure (4): Distribution of studied nurses' total practice regarding nursing care of inguinal hernia repair through the program phases

Table (3): Correlation between total knowledge and total practice among studied nurses through the program phases

\begin{tabular}{|l|l|l|l|l|l|l|}
\hline \multirow{2}{*}{ Correlation } & \multicolumn{5}{|c|}{ Total nurses' knowledge } \\
\cline { 2 - 7 } & \multicolumn{2}{|l|}{ Pre intervention } & \multicolumn{2}{l|}{ Post intervention } & \multicolumn{2}{l|}{ Follow-up } \\
\cline { 2 - 7 } & r & p-value & r & p-value & r & p-value \\
\hline $\begin{array}{l}\text { Total nurses' } \\
\text { practice }\end{array}$ & $\mathbf{0 . 1 8}$ & $\mathbf{0 . 3 4}$ & $\mathbf{0 . 8 3}$ & $\mathbf{0 . 0 0 0 * *}$ & $\mathbf{0 . 7 6}$ & $\mathbf{0 . 0 0 5}^{*}$ \\
\hline
\end{tabular}

$* *$ A highly statistical significant difference $(\mathrm{P} \leq 0.001)$

* A statistical significant difference $(P \leq \mathbf{0 . 0 5})$. 
Effect of an Educational Program on Nurses' Performance for Infants Undergoing Inguinal Hernia Repair

\section{Discussion}

The present study was a quasi-experimental study, this study aimed to evaluate the effect of educational program on nurses' performance regarding nursing intervention for infants undergoing inguinal hernia repair. This aim was achieved through assessing nurses' knowledge and practice regarding nursing intervention for infants undergoing inguinal hernia repair, designing and implementing educational program for nurses regarding nursing intervention for infants undergoing inguinal hernia repair based on actual nurses' needs.

Regarding characteristics of the studied nurses, the results of the present study revealed that, two third of the studied nurses' age was 30 years and more. This may be due to the appointment of a new staff from newly graduated nurses each year in neonatal intensive care units as the need for this critical unit to nurses. This result was similar to the result of Hassan, (2019) who study was about "effect of nursing intervention guidelines on nurses' performance and clinical outcomes related problems accompanying infants with

This finding disagreed with Nour eldeen, (2016) who study was about "Assessment of Nurses Knowledge about Pre and Postoperative Care in Pediatric Surgical Unit in Elddamer City" and clarified that near three quarter of studied nurses had bachelor degree of nursing.

The finding of the current study showed that less than two third of studied nurses, had 10 years and more of experience, this result probably due to old age of the studied nurses as there is few number of newly appointed nurses in surgical units. This finding was similar to the result of Ismail, (2013) whose study was about "Effect of A Protocol of Immediate Pre and
Hirschsprung disease" and found that eighty percent of the studied nurses were 30 and more years.

This finding disagreed with Ahmed, (2014) who study was about "Quality of Nursing Care Provided for Neonates with Tracheoesophageal Fistula" and found that, the highest percentage of nurses their age ranged from 20 to less than 30 years old.

In relation to nurses' qualifications, more than half of the studied nurses had nursing diploma (secondary nursing school) certificate, this may be due to the fact that nursing secondary school provide the community with large number of graduate diploma nurses than other agencies such as faculties of nursing. This finding is similar to the result of Ibrahim, (2016) who study was about "Nurses' Knowledge and "Practice regarding Pre and Postoperative Nursing Care Provided for Children with Intestinal Obstruction" who reported that two thirds of nurses were graduated from diploma secondary school of nursing.

Postoperative Nursing Intervention on the Occurrence of Shunt infection in Children with Shunted Hydrocephalus" who revealed that more than two thirds of nurses had 10 or more years of experience.

This result was incongruent with the result of Mohammed \&Abas, (2017) who study was about "Effectiveness of an Educational Program on Nurses' Knowledge Concerning Medication Error at Teaching Hospital in AL-Nasiriyah City" who reported that the majority of both control and study groups of nurses had (1-5 years) of experience .

The result of the current study revealed that the majority of the studied infants' age was less 
than 6 months. This result reflects the affected age group diagnosed with inguinal hernia in infancy period. Concerning gender of studied infants, It Illustrated that more than three quarters of infants undergoing inguinal hernia repair were males, this finding because of the incidence of inguinal hernia is more in male infant than female. This result is supported by Kasper \& Wang, (2019) who mentioned that inguinal hernia can occur at any age, but the peak incidence is during infancy period and early childhood with $80-90 \%$ occurring in males. Two third of infancy and childhood hernias appear in the first 6 months of life.

Concerning infants type of inguinal hernia, this study results showed that more than one third of studied infants undergoing inguinal hernia repair were diagnosed with right inguinal hernia while less than one third were diagnosed bilateral inguinal hernia and more than one quarter were diagnosed with left inguinal hernia. This result was in agreement with the result of Mulenga et al., (2018) who study was about "Risk of Incarceration of Inguinal Hernias among Pediatric Patients awaiting elective Surgery at the University Teaching Hospital" who stated that inguinal hernias are found variously on the right side in more than three quarters of cases and on the left side in one quarter.

The finding of the current study revealed that the minority of studied infants undergoing inguinal hernia repair had family history of inguinal hernia, this result may be explained that family history is one of the risk factors of incidence of inguinal hernia in infants. This finding was similar to the finding of Abdelghaffar, (2017) who revealed that approximately $11.5 \%$ of cases of infants diagnosed with inguinal hernia, other members of the family have also had a hernia at birth or in infancy.

Regarding the order of birth the present study showed that less than half was first in order; this result was in agreement with Shyam, (2018) who study was about "Clinical Profile of Inguinal Hernia in Infants" who mentioned that, regarding the order of birth, less than two thirds of infants with IH in his study were 1st in order.

Regarding total knowledge score about inguinal hernia and nursing intervention of infant undergoing (I.H) repair, the study revealed that less than one quarter of studied nurses scored good knowledge regarding inguinal hernia and nursing intervention of infant undergoing (I.H) repair in preprogram intervention. This could be attributed to insufficient theoretical background and lack of updating nurses' knowledge through pre and postoperative nursing care training program or conference during work that emphasize on nursing care for children with surgical diseases, invariability of books especially in this area which help nurses to get the required knowledge whenever they need.

On the opposite immediately post program intervention, the majority of studied nurses were sored good regarding total knowledge about inguinal hernia and nursing intervention of infant undergoing (I.H) repair. It could be explained as the content of educational program which was developed based on nurses' needs, its clarity and simplicity, using of audiovisual materials, booklet, and availability of researcher for more clarification, using simple language, and frequent repetition to fix knowledge. This result was agreed with the 
result of Hassan, (2019) who found that the majority of nurses had good score about total knowledge after implementation of intervention guidelines.

Furthermore, in follow up program intervention (after three months), the total knowledge score of nurses reduced as more than half of them had good scores regarding inguinal hernia and nursing intervention of infant undergoing (I.H) repair in follow up program intervention. This result could be explained by the fact that, knowledge retention is usually affected by the time. This finding in agreement with Deshpand, (2015) who reported that nurses total scores of subtotal knowledge increased immediately after the program, and continued to be higher at the first and subsequent follow up phases with statistically significant difference.

There was highly statistically significant difference between nurses' knowledge about inguinal hernia and nursing intervention for infants undergoing (I.H) repair in almost of knowledge items pre and post program intervention. Also there was a statistical significant difference in the items post and follow up program. This may indicated to the effectiveness of program implementation in improvement of the studied nurses' knowledge about $\mathrm{IH}$ and nursing interventions for infants undergoing IH repair.

This finding supported by Mohammed et al., (2016) who study was about "Impact of an Educational Program in Improving Nurses' Performance among Restrained Children" and showed that there was a statistical significant difference of total nurses knowledge throughout the three phases(pre, post and follow up) of the program.
According to The American Association of Colleges of Nursing (AANC), (2016) the formal training courses play an important role in enhancing and updating nurses' knowledge and performance besides improving the quality of care.

Concerning nurses' total practice about inguinal hernia and nursing intervention for infants undergoing inguinal hernia repair, the findings of the study revealed that, more than half of studied nurses were scored unsatisfactory in their total practice before implementation of the program, this finding may be due to absence of continuous training program for nurses. This result was consistent with the result of Hussein and Rada (2016), who found that the majority of nurses had unsatisfactory performance regarding pre and postoperative care for infants with intestinal obstruction before application of educational guidelines.

Also, immediately post program intervention, the majority of studied nurses were scored satisfactory in their practice regarding inguinal hernia and nursing intervention for infants undergoing inguinal hernia repair in post program intervention. Moreover, less than three quarters of studied nurses were scored satisfactory in their practice regarding inguinal hernia and nursing intervention for infants undergoing inguinal hernia repair in follow up program intervention.

This finding may be attributed to the practical training part of the educational program, in addition to the theoretical and practical contents of the booklet which were effective in modulating nurses' practice as the nurses acquired new knowledge and skills and they were able to apply it in their practice. Regular 
training and education of nurses working in surgical units is an important factor in providing nurses with essential knowledge and skills as the nurse has an essential role in providing pre and postoperative care for infants undergoing inguinal hernia repair and prevent complications.

This result was in accordance with the result of Hashem \&Abusaad (2016), who study was about "Improving Nurses' Knowledge and Practices Regarding the Care of Children with Intestinal Stomas" who clarified that the majority of the studied nurses had incompetent level of total practices before program implementation while, there was a satisfactory level of nurses' practice in majority of them about care of children with intestinal stoma immediate post and after 3 months of the educational program implementation. Also, this result was supported by Mohammed et al., (2016) who stated that nurses' practice was improved after implementation of educational guidelines and this improvement was extended throughout the follow up.

Moreover, in accordance with Deshpand, (2015) who stated that the basic nursing knowledge that the nurse had acquired during educational teaching helped in the efficiency of the care given by the nurse and improves the quality of care.

The result of the present study revealed that there was a strong positive relation between total knowledge of studied nurses and their total practices at pre and immediately post intervention and follows up intervention. There was a highly statistical significant difference between nurses' knowledge and their practice in pre and post intervention. This can be explained in the light of enhancing and updating nurses' knowledge plays an important role in improving the quality of care given to infants undergoing inguinal hernia repair. Moreover, this result may be due to that knowledge alone without practice had no effect. As well as knowledge with practice improved nursing care for infant with inguinal hernia.

This result was in accordance with the result of Hassan, (2019) who found that there was a positive correlation between total knowledge of nurses and their total performance scores of care for infants with hirshsprung disease among the study group before, immediately after and one month after implementation of intervention guidelines.

Also this result was supported by Taha and Abd Elaziz, (2015) who stated that there was a strong positive correlation between nurses' knowledge and practice scores, which revealed that the importance of the theoretical element of guidelines. According to, this result was in accordance with the result of Carol, (2015) who mentioned that nursing education and practice have interdependent relationship, each stimulates and reflects the other's progress and each one is affected by changes in the other. This may reflect the importance of integration between theory and practice.

On the contrary, the results of Ahmed, (2014) who stated that there was negative correlation between total nurses' knowledge and performance regarding Tracheoesophageal Fistula.

\section{Conclusion}

Based on the current study findings, it can be concluded that the majority of the studied nurses had good level of knowledge, and satisfactory level of practice post program intervention with highly statistical significant 
improvement as compared to preprogram intervention. Moreover, there were positive correlation between the studied nurses' total knowledge and their total practice scores regarding pre and postoperative nursing care for infants undergoing inguinal hernia repair pre and immediately post program intervention and follow up intervention.

\section{Recommendations}

Based on the findings of the present study, the following recommendations are suggested:

-Establishment of central in-service educational department in hospital to refresh nurses' knowledge and practice periodically regarding pre and postoperative nursing care for infants undergoing inguinal hernia repair and also other surgical conditions.

-Provision of manual handbook containing all necessary knowledge about nursing care procedures related to pre and postoperative care for infants undergoing inguinal hernia repair and other problem in pediatric surgery unit.

-Periodic nursing performance evaluation against certain policy standards established by the hospital to detect points of strength and weakness to act on.

\section{References}

Abdelghaffar A., (2017). Inguinal Hernia in Infancy and Children, Chapter 5 Available at:

http://www.intechopen.com/books/hernia 8-12-2019.7.00 PM.

Abdelmohsen S., Magdy S., and Mohamed $O$. (2017): Current trend in the management of huge recurrent inguinal hernia in Infants, a Case Series. J Palliate Care Pediatric 2(2): 66-71.
Ahmed R., (2014). Quality of Nursing Care Provided for Neonates with Tracheoesophageal Fistula, Master Thesis, Faculty of Nursing, Benha University: P. 104.

Ashcraft K., Holcomb G., and Murphy J., (2016). Ashcraft's pediatric surgery. $6^{\text {th }}$ ed.: London: Saunders Elsevier Co., Pp.319-321.

Carol C., (2015). Application and Development of Pediatric Nursing Guidelines, Journal of Pediatric Nursing, 88(26): 81-88.

Daral C., (2019). Inguinal hernia. Available at: https://www.nursespost.com/inguinalhernias/.16/10/2019.9:30 PM.

Deshpand R., (2015). Effectiveness of planned nursing intervention on knowledge and practice of selected aspects of care provided for children with colostomy admitted in hospitals of Mumbai. Innovation Journal of Nursing and Health Care; 1(2):151-556.

Dougherty L. and Lister S., (2015). The Royal Marsden Hospital: Manual of Clinical Nursing Procedures, $9^{\text {th }}$ ed. Wiley Blackwell: Chi Chester Co., pp.:789 - 800, p.: 985.

Hashem S., and Abusaad F., (2016). Improving Nurses' Knowledge and Practices Regarding the Care of Children with Intestinal Stomas, Pediatric Nursing Department, Faculty of Nursing, Mansoura University, Egypt. Journal of Nursing and Health Science; 5 (6) Ver. II PP: 101-109.

Hassan M., (2019). Effect of Nursing Intervention Guidelines on Nurses' Performance and Clinical Outcomes Related Problems Accompanying Infants with Hirschsprung Disease, Doctorate 
Thesis, Faculty of Nursing, Tanta University, pp. 103-108.

Hockenberry M., and Wilson D., (2015). Wong's Nursing Care of Infants and Children, $10^{\text {th }}$ ed.: U.S.A.: Mosby Co.: pp.: 448:455.

Hussein S., and Rada A., (2016). Effectiveness of an Educational Program on Nurses' Knowledge Concerning Preoperative Care of Children Undergoing Intestinal Obstruction Surgery at Pediatric Teaching Hospitals in Baghdad City. International Journal of Science and Research Publications; 6(11):486-90.

Ibrahim H., (2016). Nurses' Knowledge and Practice regarding Pre and Postoperative Nursing Care Provided for Children with Intestinal Obstruction, Master Thesis, Faculty of Nursing, Benha University, p.96.

Ismail H., (2013). Effect of A Protocol of Immediate Pre and Postoperative Nursing Intervention On the Occurrence of Shunt Infection in Children with Shunted Hydrocephalus, Master Thesis, Faculty of Nursing, Benha University, pp. 99-101.

Kasper S., and Wang L., (2019). Assessment and Management of Inguinal Hernia in Infants, the American Academy of Pediatrics; 130:768-773.

Matti P., (2017). Fundamentals of Pediatric Surgery, $5^{\text {th }}$ ed.: Untied States of America: Springer Science and Business Media Co.; pp.: 465.-269.

Mohammed B., El- Dakhakhny A., Bassam S., and Abo Zaid A., (2016). Impact of an Educational Program in Improving Nurses' Performance among Restrained Children, Doctorate thesis, Faculty of
Nursing, Zagazig University, Zagazig Nursing Journal ; 12(1). pp.:5-7.

Mohammed H. and Abas S., (2017). Effectiveness of an Educational Program on Nurses' Knowledge Concerning Medication Error at Teaching Hospital in AL-Nasiriyah City, University of Baghdad, Nursing College. International Journal of Science and Research: Volume (6): 8, pp.:2141-2142.

Mulenga M., Bvulani B., and Munkonge L., (2018). Risk of Incarceration of Inguinal Hernias among Pediatric Patients awaiting elective surgery at the University Teaching Hospital, Lusaka, Zambia, Department of Surgery, University of Zambia School of Medicine, Lusaka, Zambia: Medical Journal of Zambia; 45 (4): 189 - 195.

Noureldeen S., (2016). Assessment of Nurses Knowledge about Pre and Post-operative Care in Pediatric Surgical Unit in Elddamer City, Master Thesis, Faculty of Graduate studies and Scientific Research, Shendi University, PP: 34-36.

Puri P., (2018). Newborn Surgery, $4^{\text {th }}$ ed. United States of America: Ataylor and Francis Co., P.: 658 -67.

Shyam K., (2018). Clinical Profile of Inguinal Hernia in Infants, Institute of Medical Sciences and Research, Coimbatore, Medical University. (3):51-54.

Taha N., and Abd Elaziz N., (2015). Effect of Nursing Intervention Guidelines on Nurses' role, patients' needs and Visual problems post cataract surgery. American Journal of Nursing Science; 4(5):261-9.

The American Association of colleges of Nursing, (2016). The impact of education 
on nursing practice. Journal of Nursing; 43(2):142-16.

Tkaz N. and Carmel A., (2016).Nursing Care of

Pediatric Surgical Patient, 3rd ed. United
States of America: Jones \&Bartlett Learning Co., pp. 140 
تأثير برنامج تعليمي على أداء الممرضات تجاه العناية التمريضية للأطفال الخاضعين لإصلاح الفتق الإربي

فاطمة عبد الستار دسوقي - رحمة سليمان بهجت- باسمة ربيع عبدالصادق- خديجة محمد سعيد

يعد الفتق الإربي هو أكثر أنواع الفتق شيو عا بين الأطفال قبل بلوغهم العام الأول من العمر. ويجب

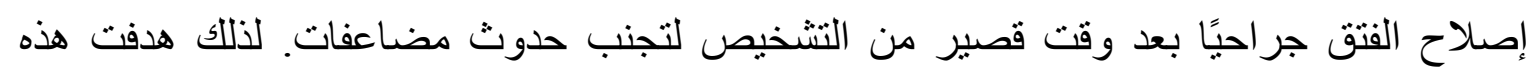
الدراسة إلى تقييم هدى تأثير برنامج تعليمي على أداء المررضات تجاه العناية التمريضية للأطفال

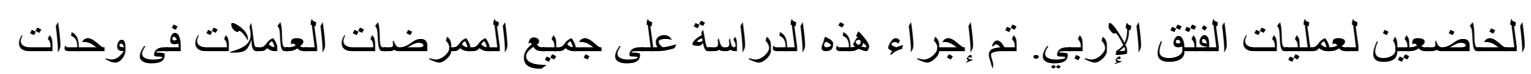

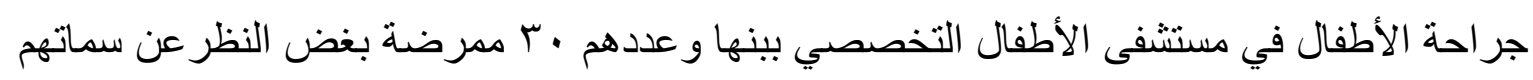

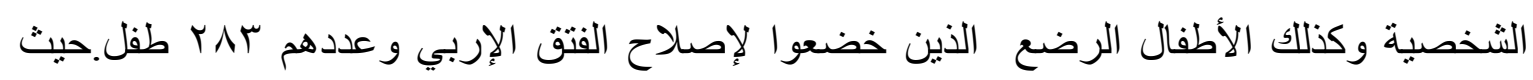

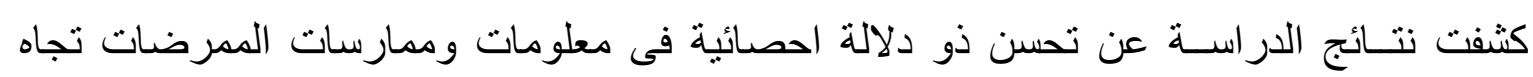

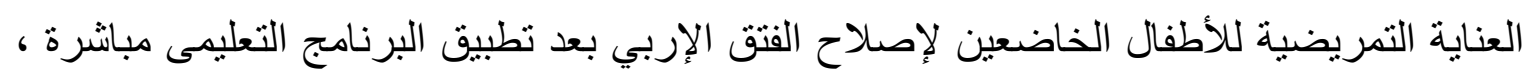

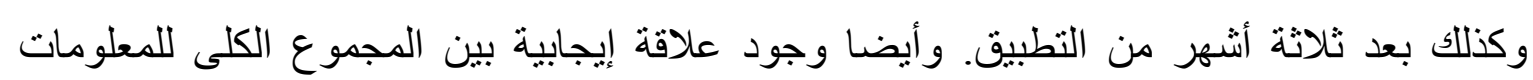

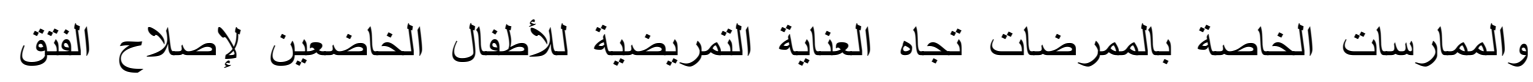
الإربي.وقد أوصت الدراسة بعقد دورات وبرامج تدريبية متخصصة بصفة دورية ومنتظمة لتعليم

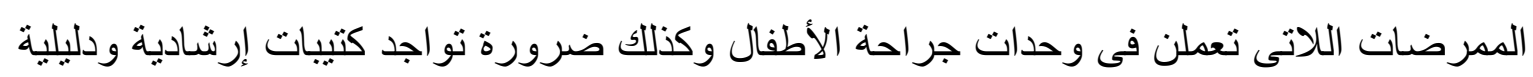
تحتوي على كل المعلومات والإجراءات الخاصة بالرعاية التمريضية قبل وبعد الجراحة لاحل للأطفال الذين يخضعون لإصلاح الفتق الإربى و غير ها من الحالات الجر احية. 